\title{
Textbook readability and ESL learners
}

\author{
DANIEL KASULE University of Botswana
}

\begin{abstract}
This paper reports activities (as part of a university course in language teacher education on teaching reading) in which primary school student teachers (all ESL in-service teacher trainees) explored their own skills of determining textbook readability using an online software tool and a cloze test completed by two hundred and seventy-eight Grade Seven primary school pupils. ${ }^{5}$ Findings from the online tool were that the text was difficult. The cloze test confirmed this when it showed that only eighteen pupils could read the text unassisted while the rest were frustrated by it. The paper uses these findings to describe the challenges pupils face and how readability research is beneficial to the reading development of ESL learners if reading of academic texts is approached from the principles of the interactive view of reading; of cognitive learning theory; and of second language acquisition theory. It is concluded that teachers' awareness of readability issues is helpful for effective reading instruction during the critical formative years of school.
\end{abstract}

\section{Introduction}

An early definition of readability by Dale and Chall (1949) included the concept of interest, but since textbooks are not read because they are interesting, readability will be understood simply as the ease or difficulty with which the textbook may be understood. Very appropriate for this paper is the view of reading as an interactive process between the reader, the text, and the writer, captured by Prins and Ulijn (1998:141) where they define readability as the ability of the text to communicate the intention of the writer to the intended reader. An important observation is that each chapter in a textbook offers particular challenges. For purposes of classroom teaching therefore, textbook readability implies assessing readability chapter by chapter.

As a language teacher educator I am concerned about my student teachers' awareness of the readability of the textbooks which they find recommended for use in the classes they teach. I therefore set out to bring this awareness to them, recognising that in many under-resourced classrooms, the textbook

${ }^{5}$ In the context of primary schools in Swaziland, the term Grade refers to primary school levels for children, whose ages range from seven to fourteen years.

READING AND WRITING

Vol 2, No 1, 2011 
commands an elevated role in teaching and learning because it may be the only teaching resource on which the teachers' explanation is based. Besides the disadvantage of implanting an unquestioning view of the printed word in children, the situation places a heavy responsibility on the quality of the textbook itself in meeting appropriate criteria regarding the learner's age, educational and cultural background, and linguistic proficiency. Textbook writers need to be guided by such requirements. Therefore, the teachers' ability to determine readability levels of the textbook is crucial for effective teaching and learning.

\section{Measuring readability}

Measuring readability is a complex affair due to the many factors involved. Gray and Leary, cited in DuBay (2004:18) identify four factors affecting readability, namely: content (including propositions, organisation, coherence), style (including semantic and syntactic elements), design (including typography, format, and illustrations), and structure (including chapters, headings and navigation). Other research reported by DuBay (2004) showed that the best predictors of textual difficulty were two aspects of style, namely: semantic content (e.g. of vocabulary) and syntactic structure (e.g. sentence length). Syntactic structure can be determined using readability formulas which are strictly text-based. The view of reading as an interactive process implies the existence of text-based, reader-based, and author-based factors regarding readability. Not all these factors are quantifiable; for example factors related to communicating meaning such as legibility of print, clarity and relevance of illustrations, and conceptual difficulty are non-quantifiable. As well as these, there are factors related strictly to the reader, seven of which Bensoussan (1991: 216) identified, namely: faulty top-down processing; faulty bottom-up processing; linguistic proficiency; lack of motivation; over-motivation; familiarity with the topic; and misleading or unfocused questions. These cannot be measured by readability formulas. Instead, more time-consuming tests such as cloze tests and comprehension tests are used. Therefore, a combination of formulas (to measure text-based and author-based factors) and tests (to measure reader-based factors) provides a more reliable assessment of the readability of a given textual item.

Teachers who are familiar with a topic can determine the suitability of written material for their pupils. However, Johnson (2000:2) claims that teachers usually under-estimate the difficulty of the text by up to 8 years and adds that the more familiar the subject teacher is with the topic, the less likely s/he probably is to see the problem from the pupils point of view. Therefore, it is recommended that readability be objectively determined using formula and cloze tests (Agnihotri and Khanna 1992, Johnson 2000). It is estimated that there 
are over two hundred formulas (DuBay 2004). These are free, online computer software tools, activated by simply cut-and-paste techniques and they calculate various readability measurements, using formulas which go by different names such as Coleman Liau index, Flesh Kincaid Grade Level, Automated Readability Index (ARI), and SMOG (Anonymous 2007, a). The calculations indicate the number of years of education that a person needs to have completed to be able to understand the text easily on the first reading. They also indicate sentences considered complicated due to the number of words and the syllables in them. The estimated readability by age, called 'reading age', means a reader of that age could just cope with the text (Johnson 2000).

Cloze tests, on the other hand, are based on the theory that readers are able to fill in the missing words as their reading skills improve. Cloze tests are becoming the object of intensive research with over a thousand studies reported (DuBay, 2004:22). The word cloze is derived from the word 'closure', a term associated with Gestalt psychologists, who maintain that human behaviour is motivated by the need for wholeness or completeness. Teachers do better to regard reading as a meaning-making activity, a principle on which cloze tests are grounded. Unfortunately, when meaning fails, reading becomes frustrating. From the theory of second language acquisition (SLA) we learn that individuals benefit from input and interaction. During reading, individual readers interact with input in the form of print. Research on L2 oral skill development (Ellis 1984:86) shows that in classroom settings, SLA benefits both from input and teacher interaction. Ellis adds that it is the interaction itself that aids acquisition. Classroom reading that merely stops at recognising the printed words (input) leaves many classroom readers frustrated. This teacher-student interaction provides what Krashen (1985: 2004) refers to as acquisition-rich, comprehensible input, which is slightly above the child's present level of competence; is interesting; is received in sufficient quantity from the text and the teacher; and is produced in a low anxiety environment.

Krashen's (1985) affective filter hypothesis informs us that language learners block off input if the atmosphere is filled with anxiety, uncertainty, threats, and is not motivating. So Krashen's affective filter hypothesis cautions that it is not just the quantity of reading alone, but also how much of it is comprehensible (Krashen, 1985); or, according to Ellis (1986), how much of it is convertible into intake. Additionally, how often pupils are assigned texts to read may indicate very little in terms of their reading-skill development. For instance, are pupils interacting with new ideas and formulating questions (interactive processing), or are they merely responding automatically to what the text is throwing at them (bottom-up processing)? A balance of these two processes benefits their reading-skill development. 
Additionally, teachers are the most knowledgeable people about the norms of linguistic competences of the children they teach. These norms assist in assessing the difficulties children would meet based on sentence analyses. Because the norms are known to them they form a psycholinguistic theory that informs the teacher about what the individual readers in the class can be expected to understand in a text. With this knowledge, planning to minimise the textual difficulties is possible.

\section{The study context}

One contextual problem is that many developing countries are facing an everincreasing school population. In Swaziland, where this study was conducted, there is a noble goal to "increase access to the lower levels of the education system by making basic education free and compulsory" (UNDP and Swaziland Human Development Forum, 2001:108). According to the Central Statistics Office (2005), there are 555 primary schools with an enrolment of 22,1956 pupils (up from 21,8352 in 2004). The same source also puts the teacher-pupil ratio at 1:33 at primary school. It is however common to find classes with ratios much higher than this figure. Working in crowded classrooms casts doubt on the effectiveness of reading instruction. In an environment where textbooks are centrally chosen on a one-suits-all basis, the textbook becomes a potential source of reading problems for particular children. Needless to say, the textbook may not be available in sufficient numbers for every child to have a copy and/or may be too old and overused between several generations of users, rendering its physical state uninspiring.

There is therefore a need to explore ways of developing effective reader-authortext interaction in the classroom. However, working with academic texts that are written in a language in which one is not competent, as is the case in ESL classrooms, is not easy. Nor can young readers readily make easy use of their home languages as resources for understanding and arguing, because these languages are not used in school, and are thus not developed for use in academic discourse. So students cannot turn to these languages as support for their processing of concepts conveyed in the unfamiliar language of the text book. And the teachers' explanation, which is based on information derived from the textbook, is conveyed in the same unfamiliar language that they are struggling with. Under these circumstances, disentangling the nature of reading problems for the purposes of reading instruction can be a complex task. Studies that are grounded in the interactive view of reading (Greene 2001, Prins and Ulijn 1998, Dean et. al 2006, Cutting and Scarborough 2006, Bensoussan 1998, Singhal 1998) indicate that in addition to learner-based factors (such as the learners' linguistic proficiency), problems also arise from the text 
itself. For example, Deane et al (2006) reviewed several studies that showed that across school levels, texts shift from being primarily narrative to being expository in nature and use increasingly sophisticated vocabulary, and more complex syntactic patterns. Therefore, in addition to learner-based factors, understanding text-level difficulties can help predict the chances of successful interaction between reader, writer and text. With regard to textbooks, children's linguistic proficiency may either refer to the ordinary language contained in the text which the children have not yet fully mastered; or to the technical language used across the entire textbook which changes from one topic to another; or to both of these.

All the above insights were helpful in combining the use of online software tools and the cloze test so as to allow a cognitive assessment of the readers, their application of interactive text processing, and their knowledge of English sentence structure for purposes of reading a text that they were encountering for the first time. It was hoped that in this way the studen teachers would see the problem from the learners' point of view.

\section{The study design}

Seven student teachers undertook the study in two steps: Step one involved the use of online software computer tools to assess the readability of a retyped version of a text extracted from the chapter 'Weather and Climate' in Science Grade Seven Pupils' Book, Primary Course for Swaziland. Step two involved the student teachers using the same text as in step one to conduct a cloze test on pupils at a school of their choice during the university's mid-term break. For step one, the retyped version of the selected passage of 246 words was cutand-pasted on-line as instructed on the website http://www.online-utility.org/ English/readability, and processed by the software to give readability scores in terms of difficult level; the number of years of education needed for one to understand it easily on the first reading; and the sentences judged to be complicated and requiring improvement.

For step two, to test whether the pupils had the ability to make sense of the text without resorting to recall, the student teachers developed a cloze test following ideas from Burns et al (1988) and Taylor cited in DuBay (2004: 27). The test was prepared as follows: the first sentence was left intact but thereafter, every fifth word was deleted. The study was conducted during February. At this time of the year, Grade Seven classes would not yet have covered the selected chapter - the test would have been invalid if they had as their answers might be based on recall rather than on a first reading. Pre-testing at nearby schools 
indicated that pupils would need more than an hour to complete the test. The pre-test also gave an idea of the kinds of answers to expect.

During pre-testing, one problem reported by the student teachers was that pupils felt very threatened, first by the test itself, and secondly by the presence of the stranger in their classroom. To minimise this effect (a) the regular teacher administered the test in the absence of the student teachers, and (b) the pupils were told that any answer was right as long as it made sense.

Each of the seven student teachers administered the test at one Grade Seven class at a school of their choice. The result of this random choice was one urban, and six rural schools were used. Altogether, 278 pupils wrote the cloze test.

Pupils were directed to fill in the missing word. Pupils were not told the source of the text nor were they told that only the same word that the author had used would be marked as correct. Individual pupil performance was then graded as a percentage. The lower the score, the more difficult the text was for that individual. Based on performance in the test, readability of the text for each pupil was then given as being at one of three levels (DuBay 2004:27):

$$
\begin{aligned}
& 50-60 \%=\text { independent (unassisted reading) level } \\
& 35-50 \%=\text { instructional (assisted reading) level, and } \\
& \text { Below 35\% = frustration level }
\end{aligned}
$$

\section{Expectations}

Our initial expectation was that the cloze test would get the children to engage individually and directly with the author's language, without any interaction with anyone else, such as with each other or with their teacher. Because textbooks may not suit all readers alike, we expected that differences in performance on the cloze test would result from this factor. Our other expectation was that the reading of textbooks was a problematic activity for many children (Burns et al 1988, Johnson 2000). Grade Seven is a particularly significant period in the life of school-going children in Swaziland: it is preparation for entry to secondary school where harder texts await. It is also at these higher Grade levels that teachers more often assign students to read texts on their own. Texts at these levels more frequently use technical and specialised vocabulary and concepts. Another expectation was that readability difficulties would 
be more pronounced in non-urban primary schools since performance in national examinations often portrays urban schools as being advantaged.

\section{Findings and discussion}

The Flesch Reading Ease (Flesch RE) online software tool uses an index of zero to a hundred. The closer the score is to a hundred, the easier the content; the closer the score to zero, the more difficult. The report for the text gave a Flesch RE index of 65.76. According to the Flesch Reading Ease Table, at 65.76 the text is standard, has an average sentence length of seventeen words and contains 147 syllables per 100 words, and is suited to readers who have completed the seventh or eighth Grade, based on US standards (Anonymous 2007, b). This finding shows that the text is slightly above the level it is intended for use in Swaziland. We thought that this might not necessarily be a bad thing as it offered a slight challenge to the targeted readers.

The number of years of formal education that were required so as to understand the text on first reading varied according to the formula: 9.89 on the Gunning Fog Index; 9.35 on Coleman Liau Index; 7.30 on the Flesh Kincaid Grade level; 7.00 on the ARI; and 10.11 on the SMOG index. Again, whichever index was used, the text was predicted to be challenging at the Grade Seven level in Swaziland schools, for which it was intended. Both findings can serve to challenge common assumptions among teachers that a textbook recommended for use by the Ministry of Education automatically matches the abilities of the children in the classroom and therefore requires no guided instruction.

At Grade seven pupils should begin to appreciate that muddle is more likely in a long sentence than in a short one no matter whether one is reading or writing it. Most writing instructors recommend fifteen to twenty $(15-20)$ words per sentence for this level of readers. The software tool reported an average of seventeen (17) words per sentence according to the Flesch Reading Ease Table (Anonymous 2007, b). This text is therefore within the recommended sentence length.

Our subjecting this text to analysis by the online tool might appear ill-conceived as the tool was intended for use in a completely different context. However, since the analysis involved purely mathematical calculations of sentence length, syllables per sentence and number of sentences in the text, it is justified. The tool analysed syntactical features that have been confirmed in several studies (DuBay 2004, Deane et al. 2006, Bensoussan 1998, Prins and Ulijn 1998, Greene 2001) as factors in readability. 
The tool also listed the following five sentences which it suggested needed rewriting in order to improve readability of the text:

Coastal regions near oceans and large lakes may have different climates than other regions at the same latitude and altitude.

LATITUDE: Regions at low latitudes near the equator have hot climates because the sun's rays shine more directly there.

It can be freezing, with snow at the top of a high mountain, even on a mountain located in a hot part of the earth.

However, the average weather over a large region is usually quite similar from year to year.

Swaziland residents are familiar with weather and climate differences at different altitudes.

These five were among the longest sentences in the text. They also contain several words with more than two syllables. The five were therefore assumed to cause difficulty. For purposes of classroom teaching, this finding implies that teachers would do better to regard sentence length and word length in a text as potential causes of difficulty. (Harrison cited in Agnihotri and Khanna (1992:284) informs us that the longer a word is, the more likely it is to be rare.)

Table One, below, reports, class by class, on the performance of the 278 Grade Seven pupils on the cloze test. It is notable that class sizes were above the norm of 1:33 given by Swaziland's Central Statistics Office (2005). As O'Sullivan (2006) observed, overall teacher-pupil ratios are not an accurate reflection of actual class-size as they are obtained by dividing the number of teachers in a school by the number of pupils, without considering the common practice of subject teaching, for example. Unlike class teaching, subject teaching, which is common in upper primary and secondary school, increases the number of teachers in a school thereby making the teacher-pupil ratio appear lower than it actually is in certain subject specific classes. As noted earlier, a large class impacts negatively on the effective teaching of reading. 
Table 1: Number of children by category of readability

\begin{tabular}{|c|c|c|c|c|c|c|c|}
\hline Level & $\begin{array}{c}\text { Class } \\
\mathrm{A} \\
\mathrm{N}=47\end{array}$ & $\begin{array}{c}\text { Class } \\
\text { B } \\
\mathrm{N}=52\end{array}$ & $\begin{array}{c}\text { Class } \\
\mathrm{C} \\
\mathrm{N}=20\end{array}$ & $\begin{array}{c}\text { Class } \\
D \\
N=31\end{array}$ & $\begin{array}{c}\text { Class } \\
E \\
N=46\end{array}$ & $\begin{array}{c}\text { Class } \\
\text { F } \\
\mathrm{N}=47\end{array}$ & $\begin{array}{c}\text { Class } \\
\text { G } \\
\mathrm{N}=35\end{array}$ \\
\hline $\begin{array}{l}\text { Independent } \\
\text { (Unassisted } \\
\text { reading) }\end{array}$ & 18 & 0 & 1 & 0 & 0 & 0 & 0 \\
\hline $\begin{array}{l}\text { Instructional } \\
\text { (Assisted } \\
\text { reading) }\end{array}$ & 3 & 2 & 0 & 0 & 0 & 0 & 0 \\
\hline Frustration & 26 & 50 & 19 & 31 & 46 & 47 & 35 \\
\hline
\end{tabular}

In Class A, the only urban sample, eighteen children in this class could read the text unassisted, three could use it when assisted, and twenty-six would be frustrated by it. Although this does not give a normal curve, it fulfilled our expectation that a recommended textbook suits individual children in a class differently. Results for the other six samples from far-flung places (classes B, C, D, E, F, and G) consistently show the entire class reading the text at frustration level. This finding underscores the need for classroom teachers to accept that readability is an issue. The right response is not to reject the particular textbook but, rather, to approach the teaching of reading more systematically, as we shall show later, after identifying the challenges the children faced in the cloze test.

Answers supplied by the children to the forty-seven gaps in the cloze test were analysed for patterns emerging. The patterns found to be prevalent are summed up and discussed below.

\section{Disregard for text structure, semantic and syntactic clues, and misuse of collocation}

The text comprised five short paragraphs under the heading 'Weather and Climate. The two opening paragraphs introduced the topic. The last three paragraphs followed the sub-headings 'Altitude', 'Latitude', and 'Bodies of Water', respectively. The authors had intended, no doubt, that the subtitles should serve as lead-ins to paragraph topics and hence to serve as an aid to readers' comprehension. For purposes of our study, we therefore expected the subheadings to provide clear clues to the missing word. However, as the results show, this did not prove to be the case. 
We also expected that semantic and syntactic clues implied by the context would enable gap-filling. However, our analysis of the quality of answers provided by children in the cloze test indicated a complete disregard for syntactic and semantic clues. The randomly selected sample answer below is representative of this kind of problem:

Regions at low (33) is near the equator have (34) different climates because the sun's (35) became shine more directly there. (36) Big Bend polar regions the sun (37) and low in the sky, (38) 12.00 at noon in the (39) evening time. Such regions have (40) hot temperatures most of the (41) highveld.

This child refers to 'Big Bend' which is a name of a town in Swaziland, and to 'highveld' which is a geographical region in Swaziland. The child (and there were many others) is using the geographical context of Swaziland alone and is refusing to abandon it, even when the paragraph, in its reference to 'the equator' and the 'polar regions', clearly demands a global context. Ignoring those semantic clues creates the problems. The child is not guided by signposts of sentence structure, such as when one has the 'the sun's (something)', the child supplies a verb. Readability issues at the semantic and syntactic levels relate to a reader's ability/inability to use the signposts effectively to negotiate possibilities and thus aid comprehension. When this fails, the text is read at frustration level as the results of this study show. Pointing out these features of the text could reduce the frustration arising from miscomprehension. Deane et al (2006:260) rightly observed that the reading process involves combining "information from successive sentences to understand the global communication of the text".

Difficulties arising from text miscomprehension may also be attributed to vocabulary in the text. The following technical vocabulary contributed to the difficulty: altitude, latitude, weather, climate, bodies of water, and polar regions. Because children would be required to master and recall these words as part of the content of the chapter, classroom activities would undoubtedly be more rigorous with more time on the task for this to happen than by glancing over them in their textbook. We also expected certain ordinary words in the text to have contributed to the difficulty for a Grade Seven pupil such as: factors, determines, residents, and continually.

As confirmed earlier by the online tool, sentence length increased progressively to give readers greatly expanded syntactic structures. With regard to the cloze test, such sentence expansion sometimes resulted in more blank spaces to fill within a single sentence and so, collocation and awareness of sentence structure would be important clues in this regard. For ESL children, reading a text becomes difficult because their familiarity with collocations in English 
and the many variations in the structure of the English sentence is limited. In this study the answers provided by the children tended to indicate a formulaic, rather than an analytical, approach to English syntax; for example, when the subjects saw 'latitude and ?? presence of' $33.5 \%$ (93 out of the total 278) of children immediately filled the gap with 'longitude'. Yet the correct answer was the simple word 'the'.

Equally confounding, 'the sun's rays shine' arguably a familiar collocation, proved difficult for the children to predict. Out of the total two hundred and seventy eight (278) answers, only twenty one (21) were correct (7.6 per cent of the total) largely from class A, the one urban school in the study. The frequent answer of choice was 'the sun's is shine'; and in one class, all forty-seven (47) children settled for this answer. Rather a very odd choice of answer! Although possible alternative collocations (such as 'the sun's light', 'the sun's position', 'the sun's energy' and 'the sun's heat') were wrong in the context of this study, they were given by only twenty three (23) children out of a total two hundred and seventy eight (278). This number is too small for us not to make the claim that children's approach to English syntax is formulaic at times, and at other times unpredictable, but certainly not analytical. It appears the subjects were easily misled when they relied on a more familiar formulaic utterance, namely: 'the sun is shining' frequently used to describe the day's weather and ignored the main clue in the text which is the apostrophe after the word 'sun'.

\section{The nature of the challenges}

The challenges of the cloze test on the children were enormous, recalling that the cloze test was an unexpected one and on a topic that the children had not yet covered. As the results show, a large majority were not proficient readers. And because proficient reading is not an event but a process, classroom instruction needs to plan it as a series of events that reinforce each other. Grabe (1992:50-3) offers the view that successful reading is composed of sub-skills. In our effort to understand reading-skill development we shall use Grabe's six component sub-skills of reading as a framework to analyse and tabulate the demands. On the basis of these sub-skills, classroom instruction can be planned for reading many other academic texts. 
Table 2: The demands on the children's reading skills

\begin{tabular}{l|l}
\hline \multicolumn{1}{c|}{ Grabe's reading sub-skill } & \multicolumn{1}{c}{ Demand from the cloze test } \\
\hline $\begin{array}{l}\text { The perceptual automatic } \\
\text { recognition skill }\end{array}$ & $\begin{array}{l}\text { Proficiency in bottom-up processing } \\
\text { of printed words (Cutting and } \\
\text { Scarborough 2006:278) relating to a } \\
\text { topic which was new to the children. }\end{array}$ \\
\hline Linguistic skills & $\begin{array}{l}\text { Proficiency in analysing the semantic } \\
\text { and syntactic relationship between } \\
\text { the words (Cutting and Scarborough } \\
\text { 2006:278) including the missing one. }\end{array}$ \\
\hline $\begin{array}{l}\text { Knowledge and skills of discourse } \\
\text { structure and organization }\end{array}$ & $\begin{array}{l}\text { Proficiency in recognising the use } \\
\text { of titles, subtitles, cohesive devices, } \\
\text { linking isolated bits of information } \\
\text { (Greene 2001:83) on local weather so } \\
\text { as to understand the global concept } \\
\text { 'climate' }\end{array}$ \\
\hline Knowledge of the world & $\begin{array}{l}\text { Proficiency in top-down processing } \\
\text { (Cutting and Scarborough 2006:278), } \\
\text { without the teacher's help, to bring } \\
\text { meaning to the decoded words }\end{array}$ \\
\hline $\begin{array}{l}\text { Synthetic and critical evaluation } \\
\text { skills }\end{array}$ & $\begin{array}{l}\text { Proficiency in linking the content of } \\
\text { the text to 'science' as shown in the } \\
\text { primary school curriculum }\end{array}$ \\
\hline $\begin{array}{l}\text { Metalinguistic knowledge and } \\
\text { skills }\end{array}$ & $\begin{array}{l}\text { Proficiency in making inferences } \\
\text { using contextual clues }\end{array}$ \\
\hline
\end{tabular}

The children in this study who were frustrated by the cloze test would have performed better had they developed proficiency in bottom-up and top-down processing (sub-skills 1 and 4). This is possible if they develop linguistic analytical skills (sub-skill 2) so they can effectively use the semantic and syntactic clues available in order to understand local weather before they understand global climate (sub-skill 4). Finally, they need to be able to infer that places where the sun's rays shine obliquely are cold (sub-skill 6) and so on.

This did not happen because the children had not had a pre-reading activity that stimulated using these sub-skills. We can conclude that textbook reading demands active involvement of readers for it to be successful. The demands listed in Table 2 above can form the objective of a classroom reading lesson of this text. For example, the teacher and the class identifying the function of the words in a long sentence taken from the text can respond to demands of 
skill $2,3,4$, and 6 . This makes teaching reading a skills-building activity that can be applied on a variety of texts they read in class.

\section{Recommendations}

It is not practically possible to conduct readability assessments for each chapter in a textbook before teaching it. Even the online software tools require retyping or scanning the text before it can be cut-and-pasted on the webpage. However, the findings of this study imply that determining readability is beneficial to teaching and learning, as the teacher gets a clearer view of learners' difficulties with the text. Our recommendation therefore is that since classroom teachers are the best available assessors of any mismatch between the linguistic competencies demanded by the text and the resources available to their learners, action research into the readability of school textbooks, particularly in science, would inform their decisions regarding the appropriateness and sequencing of textual content. Recognising this need means providing these teachers with skills with which to efficiently determine textbook readability.

\section{Conclusion}

One of the limitations of this study was that it was too narrow in scope and focus, since the readability of a given textbook varies from one chapter to the next. We can therefore not generalise the findings. Secondly, tools are yet to be developed that specifically assess readability of texts intended for use in English as a Second Language (ESL) classrooms where learners' linguistic norms are diverse. Such assessment would not merely be desirable for purposes of rejecting and accepting certain textbooks, but for sensitising teachers to the difficulties embedded in the text in use. It is hoped that the seven participant teachers in this study have been sensitized to the need to assess the readability of the textbook they are currently using and to view textbooks as sources of potential reading difficulties.

\section{References}

Agnihotri, R.K and A.L. Khanna, A.L. 1992. Evaluating the readability of textbooks: an Indian study. Journal of Reading 35(4): 282-288.

Anonymous 2007 (a). Test Document Readability and improve it. Downloaded January 2007 from http://www.online-utility.org/english/readability_test_and_improve.jsp

Anonymous 2007 (b). Differences among the forecast, Flesch-Kincaid, and Flesch Reading Ease Formulas. Downloaded January 2007 from http://www.utexas.edu/disability/ai/resource/readability/manual/flesch-calculate-English.html_ 
Bensoussan, M. 1998. Schema effects in EFL reading comprehension. Journal of Research in Reading, 21(3) 1998: 213-227.

Burns, P. C., Roe, B. D. and Ross, E. P. 1988. Teaching Reading in Today's Elementary Schools ( $4^{\text {th }}$ Ed). Boston: Houghton Mifflin.

Central Statistics Office. 2005. Education Statistics 2005. Mbabane: Swaziland.

Cutting, L.E. and Scarborough, H.S. 2006. Prediction of reading comprehension: Relative contributions of word recognition, language proficiency, and other cognitive skills can depend on how comprehension is measured. Scientific Studies of Reading, 10(3): 277-299.

DuBay, W. H. 2004. The principles of readability. Costa Mesa, CA: Impact Information. Downloaded November 2007 from http://www.nald.ca/fulltext/readab/readab.pdf

Dale, E. and Chall, J.S. 1949. The concept of readability. Elementary English, 26: 23

Dean, P., Sheehan, K.M., Sabatini, J. Futagi, Y. and Kostin, I. 2006. Differences in text structure and its implications for assessment of struggling readers. Scientific Studies of Reading, 10(3): 257-275.

Ellis, R. 1986. Understanding second language acquisition. Oxford: OUP.

Fry, E. 1990. A Readability formula for short passages. Journal of Reading, 33/80: 594-597.

Grabe, W. 1992. What every ESL teacher should know about reading in English. In New directions in foreign language teaching theory and practice, R. A. Rodriguez, R.L. Ortega and F. Macarthur (eds). Salamanca: Universidad.

Greene, B.B. 2001. Testing reading comprehension of theoretical discourse with cloze. Journal of Research in Reading. 24(1): 82-98.

Johnson, K. 2000. Readability and reading ages of school science textbooks. Downloaded July 2009 from http://www.timetabler.com/reading.html

Krashen, S. D. 1985. The input hypothesis: issues and implications. London: Longman

Krashen, S. 2004. Applying the Comprehension Hypothesis: Some Suggestions. Downloaded December 2004 from http://www.sdkrashen.com/articles/eta PAPER/index.html

Ministry of Education.1997. Science Grade 7 Pupils' Book, Primary Course for Swaziland. Mbabane: Swaziland.

O'Sullivan, M.C. 2006. Teaching large classes: The international evidence and a discussion of some good practice in Ugandan primary schools. International Journal of Educational Development, 2 (16: 24-36.

Prins, D.E. and Ulijn, J.M. 1998. Linguistic and cultural factors in the readability of mathematics texts: the Whorfian hypothesis revisited with evidence from the South African context. Journal of Research in Reading 21(28:139-159

Singhal, M. 1998. A comparison of L1 and L2 reading: cultural differences and schema. The Internet TESL Journal, (108. Downloaded July 2008 http://iteslj.org/Articles/SinghalReadingL1L2.html

United Nations Development Programme and Swaziland Human Development Forum. 2001. Swaziland Human Development Report, 2000: Economic growth with equity. Mbabane: UNDP 